\title{
Transmission Grid Extensions for the Integration of Variable Renewable Energies in Europe: Who Benefits Where?
}

\author{
Katrin Schaber ${ }^{a, b, *}$, Florian Steinke ${ }^{\mathrm{c}}$, Thomas Hamacher ${ }^{\mathrm{a}}$ \\ ${ }^{a}$ Institut für Energiewirtschaft und Anwendungstechnik, Technical University Munich, \\ Arcisstr. 21, 80333 Munich, Germany \\ ${ }^{b}$ Max-Planck-Insitute for Plasmaphysics, Boltzmannstr. 2, 85748 Garching, Germany \\ ${ }^{c}$ Siemens Corporate Technology, Munich, Germany
}

\begin{abstract}
Variable renewable energy (VRE) generation from wind and sun is growing quickly in Europe. Already today, VRE's power contribution is at times close to the total demand in some regions with severe consequences for the remainder of the power system. Grid extensions are necessary for the physical integration of VRE, i.e., for power transports, but they also have important economic consequences for all power system participants.

We employ a regional, power system model to examine the role of grid extensions for the market effects of VRE in Europe. We derive cost-optimal macroscopic transmission grid extensions for the projected wind and solar capacities in Europe in 2020 and characterize their effects on the power system with high regional and technological resolution.

Without grid extensions, lower electricity prices, new price dynamics and reduced full load hours for conventional generation technologies result in
\end{abstract}

*k.schaber@tum.de 
proximity to high VRE capacities. This leads to substantial changes in the projected achievable revenues of utilities. Grid extensions partially alleviate and redistribute these effects, mainly for the benefit of baseload and the VRE technologies themselves.

Keywords: Renewable energy, grid integration, merit order effect

\section{Introduction}

Political targets of the European Union suggest that $34 \%$ of the electric3 ity shall be provided by renewable energies in 2020 (EU Commission, 2006).

4 Major contributions will come from wind and solar energy due to their large 5 potential, attractive feed-in tariffs in many countries and expected cost re6 ductions (Edenhofer et al., 2010; IEA, 2011). Wind energy installations in 7 Europe grew by $10 \mathrm{GW}$ in 2009 and 2010 respectively, with additional 13 to 19 GW expected to come online each year until 2020 (GWEC, 2011; EWEA, 9 2009a). Photovoltaic installations reached 29 GW in Europe, and 17 GW in Germany alone in 2010 (BMU, 2011; EPIA, 2011). For 2020, EPIA sees a $12 \%$ share of photovoltaics in European power demand as both necessarry 12 and feasible for Europe to achieve its $\mathrm{CO}_{2}$ reduction goals (EPIA, 2009).

Wind and solar energy, however, are not just another type of power plant 
plant park is needed, see e.g. TradeWind (2009), where the capacity credit of wind is only rated at 10-16\% on a European level. The capacity credit of wind and solar energy is the dependable share of the VRE capacity, i.e., the amount of other generating capacity that can be removed from the system without reduction of the security of supply. Thus, most of today's power plant park will have to stay online for a significant period of time, but with strongly reduced full load hours (FLH).

The second difference is that generation from VREs is subsidized through feed-in tariffs in many countries. Together with extremely low variable generation cost, this significantly changes electricity markets and their price dynamics. Third, VRE generation is not spread uniformly over Europe; instead it is centered in regions with high meteorological potential and a supportive political environment, while the current power generation infrastructure is aligned with load centers. This generally calls for more transport capacities, whose realization faces several barriers, such as public acceptance and very long planning periods. In the mean time, above mentioned effects of VREs on electricity markets and conventional power plants will be experienced very differently in different regions of Europe.

These qualitative arguments motivate our study. We employ a benchmarked, Europe-wide, power system model based on Heitmann (2005) and Haase (2006) to analyze the role of grid extensions for the market effects of the projected wind and solar capacities for 2020 in Europe. We quantify the regional economic effects of VREs on electricity markets and their participants in dependence of different grid extension levels. We investigate the potential of grid extension to reduce the effects of VREs to the electricity 
market. Economic benefits for utility owners, but also potential additional barriers to grid extensions are identified.

The model is based on minimization of overall system costs. We determine cost-optimal transmission grid extensions. Also, schedules for conventional power plants, storage facilities and grid operation is determined by the model. Nodal marginal pricing allows us to predict electricity prices.

Our paper proceeds as follows: In Section 2 we review related work. The model is described in detail in Section 3. We derive our results in Section 4, where we first focus on cost-optimal grid extensions and second, analyze the effects of VRE to the existing power system. In Section 5 we discuss our results before concluding in Section 6 ,

\section{Related Work}

The challenging properties of VREs, namely variability, uneven geographical distribution and vanishing variable cost, spurred numerous research efforts.

Concerning the first two issues, technical analyses have been conducted to identify measures how VREs can be integrated in power systems, such as storage, demand side management, grid extensions and more flexible power plants. Grid extension are thus one possible way to smoothen fluctuations and gain access to areas of high VRE potential. Giebel (2000) and Heide et al. (2010) quantify the statistical advantages of interlinked VRE generation, such as reduced need for backup and storage capacities. Technical and geographical feasibility studies show, that a European supergrid, i.e., a powerful high voltage grid, facilitates visionary renewable scenarios 
for Europe (Biberacher, 2004; Czisch, 2005; DLR, 2006). Also, a recently published Roadmap (McKinsev et al., 2010) and wind integration studies (Greenpeace and 3E, 2008; EWEA, 2009b) judge grid extensions as necessary on the medium and long term to overcome excess electricity production and high backup capacity needs. Which lines to extend precisely has mainly been identified on a national level, in response to recent wind and solar capacity developments (for Germany: Dena (2005, 2010); Heitmann and Hamacher (2009); Weigt et al. (2010)).

In addition to the temporal and geographical variability of wind and solar energy, their low level of variable costs has severe consequences on the electricity market: VREs and many other renewable energies have negligible variable costs and, therefore, rank first in the merit order: they are the cheapest power supply source in terms of variable costs. Due to this cost structure and additionally fixed by the regulator through priority feed-in laws, the supply curve, i.e., the sorted variable costs of all available power plants, is shifted whenever renewable energies contribute to the satisfaction of demand. As a consequence the demand curve intersects the supply curve at lower prices and the price level declines due to renewable supply. This is called the merit order effect. Sensfuss et al. (2008) show in an econometric analysis, that in 2006 the German mean wholesale electricity price was lowered by $7.8 € /$ MWh by this effect due to the integration of renewable energies. This results in a redistribution of economic welfare: consumer surplus increases and producer surplus is reduced (see also de Miera et al. (2008)). Based on the example of Texas, Woo et al. (2011) show that higher wind energy supply leads not only to lower average electricity prices, but also to higher price volatility. 
94 This volatility is sensitive to the level of wind speed, the behavior of different market participants (Green and Vasilakos, 2010) and the distribution of 6 market power, as proven in a theoretical framework by Twomey and Neuhoff 7 (2010). Based on a probabilistic power generation model MacCormack et al. (2010) point out, that opposite to the sinking electricity price, the total costs of the power supply rises with increasing wind contribution. Measures to alleviate the effects of VREs to the electricity price are investigated by Jacobsen and Zvingilaite (2010) for Denmark focusing on storage, demand side management and real time pricing. Leuthold et al. (2009) demonstrate, that the reduction of electricity prices due to wind integration can be diminished with grid extensions in Europe. They find, that European grid extensions lead to an overall welfare gain.

In this study we determine cost-optimal grid extensions for Europe in 2020 to integrate VREs and investigate the role of the grid for electricity markets and their participants. The studies mentioned above showed the necessity of grid extensions and the effects of VREs to the electricity prices in general. We apply a regionally resolved power system model based on linear optimization which includes electricity transport between regions and allows to determine necessary grid extensions. Our methodology allows to draw conclusions for each region and generation technology in detail. We quantify changes in power producer revenue due to VREs as well as the effect of grid extensions for each generation technology type in order to identify possible proponents and opponents to grid extensions for VREs in Europe. 


\subsection{Model Formulation}

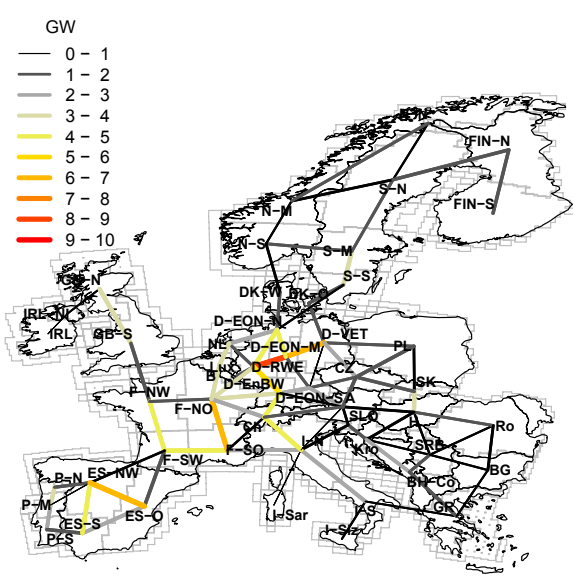

Figure 1: European model regions with aggregated ENTSO-E transmission grid

\section{The Model}

The applied methodology in this study is a power system model based on linear optimization of overall costs from a social planner perspective. The model, called URBS-EU, is an extension of the German energy system model URBS-D (Heitmann, 2005; Haase, 2006). It divides Europe into 83 regions, 50 of which correspond to the major Transmission System Operator (TSO) regions in the European Network of Transmission System Operators for Electricity (ENTSO-E) grid and 33 to specific offshore regions (see Figure1). The temporal resolution is hourly. Thanks to this high level of detail, the model is appropriate to analyze variable resources, such as wind and solar energy.

The structure of the overall system costs subject to minimization is

$$
C O S T=\sum_{x, i}\left\{\kappa_{i}^{I} C N_{i}(x)+\kappa_{i}^{F} C_{i}(x)+\sum_{t} \kappa_{i}^{V a r} E_{i}^{o u t}(x, t)\right\}
$$


They include the annuity of investment $\operatorname{costs} \kappa_{i}^{I}$, fix, capacity-dependent Operation and Maintenance $\operatorname{costs} \kappa_{i}^{F}$ as well as the variable costs $\kappa_{i}^{V a r}$ for power plant, storage and transmission technologies. The costs per technology $i$ are given in Table 1. $C_{i}(x)$ is the total capacity, $C N_{i}(x)$ the capacity additions per technology $i$ and region $x$ and $E_{i}^{o u t}(x, t)$ is the power production per region, technology and time-step $t$. Through optimization of the total system costs, power plant dispatch, $E_{i}^{o u t}(x, t)$, per region and technology, is determined. On demand, the model also computes cost-optimal extensions of the power plant, storage and transmission infrastructure, based on the annuity of investment costs. This is achieved by using $C N_{i}(x)$ as free variable, in addition to $E_{i}^{\text {out }}(x, t)$.

The linear optimization is subject to restrictions which describe the properties of the power supply system. A complete list of the equations defining the model URBS-EU is given in Appendix A.1. The most important constraint, is that electricity demand $d(x, t)$ has to be satisfied in each region and time-step:

$$
\sum_{i} E_{i}^{o u t}(x, t)-E_{\text {Transmission }}^{\text {in }}(x, t)-E_{\text {Storage }}^{\text {in }}(x, t) \geq d(x, t) .
$$

In the energy balance (equation 2), the electricity export $\left(E_{\text {Transmission }}^{\text {in }}(x, t)\right)$ and feed-in to storage $\left(E_{\text {Storage }}^{\text {in }}(x, t)\right)$ have to be taken into account. The dual solution to this equation gives the marginal costs of electricity generation. Assuming a well functioning electricity market, the marginal costs are a good indicator of the wholesale electricity prices (Borchert et al., 2006). The marginal costs are determined by the variable costs of generation, storage 
and transmission. Transmission and storage losses indirectly translate into increased marginal and total costs, as they lead to higher demand for power generation (see equation 2). In our model, excess production is possible. To ensure stable operation of the power system, generation that exceeds demand has to be discarded. If no excess production was allowed for, negative price would occur. So in our model, negative prices are not taken into account. This approximation is justifiable, as in reality negative prices occurred only in very few hours in the past (EEX, 2009). Moreover, negative prices will most likely be compensated by market participants, who create additional demand such as thermal storage for example and take advantage of the negative price events.

Further restrictions to the cost-optimization are maximum generation constraints for each generation and storage technology and region:

$$
E_{i}^{o u t}(x, t) \leq a f_{i} \cdot C_{i}(x) .
$$

Reduced average availability of power plants due to planned and unplanned outages are included with an availability factor $a f_{i}$. Similar upper bounds for storage and transmission capacity are included in the model and storage and transmission losses as listed in Table 1 are taken into account. Hourly values of the capacity factor $c f_{i}(x, t)$ for VREs serve as constraints to the operation level of variable renewable technologies. The time dependent capacity factor is deduced from meteorological data (see Subsection 3.2 and Heide et al. $(2010))$

$$
E_{i}^{\text {out }}(x, t)=c f_{i}(x, t) \cdot a f_{i} \cdot C_{i}(x) \quad, \forall i \in V R E \quad c f_{i}(x, t) \in[0,1](4)
$$


where $V R E$ includes wind on- and offshore, solar PV and also run-off river hydro power plants.

Technology specific ramping constraints, i.e., a speed-restriction for changes in electricity generation, are included in the model.

$$
\left|E_{i}^{\text {out }}(x, t)-E_{i}^{\text {out }}(x, t-1)\right| \leq p c_{i} \cdot C_{i}(x)
$$

The maximal power change $p c_{i}$ per technology is listed in Table 1, Ramping constraints are crucial to model power plant dispatch with a linear optimization model. Commonly more realistic results can be achieved with unit commitment models, who require Mixed Integer Programming and are computationally expensive. Aboumahboub (2011, Ch. 2.4) shows that through the inclusion of ramping constraints in linear models, the results from linear optimization and a unit commitment model converge. Ramp-up costs are not included, but the above restriction leads to an increase in total costs, as it constrains the cost-optimal dispatch of power plants and can lead to higher power generation.

We perform a simplified simulation of electricity transmission between regions. Kirchhoff's first law, the conservation of currents in each node of an electricity network, is respected in our model, while the second, the voltage law, is not included. Electricity transmission is thus modeled as a transport problem, neglecting effects of load flows (see Appendix A.1). The approximation of electricity transmission with a transport model allows to keep the optimization problem linear and to optimize grid extensions and power plant additions and operation simultaneously.

The model is formulated and optimized using the General Algebraic Mod- 
eling System (GAMS) software package. The optimization is performed for six representative weeks of each year of available meteorological data (20002007). The selected weeks include the minimal and maximal residual electricity demand, are distributed uniformly across seasons and have minimal deviation from the respective annual full load hours (FLH) of wind and solar (less than 3\%). Model results are presented as aggregation over the eight years of available data, where energy-related parameters are averaged over the eight years and for capacities, the maximal values are presented.

\subsection{Model Data}

The cost assumptions and the technical parameters, shown in Table1, are based on scientific studies (IEA, 2010b; McKinsey et al., 2010; PWC et al., 2010) and industry expert evaluations. Technical parameters, such as conversion and transmission and storage losses $\eta_{i}$, ramping constraints and restricted availability, are included also listed in Table 1. The ramping constraints includes the technical ramping restrictions for each individual power plant, but also the inertia of the aggregated generation capacity per generation technology in each model region. Here some power plants might be shut of and have to respect minimal time of non-use or cold start restrictions. As a results, aggregated ramps are slower than individual ones.

To model wind and solar energy supply, we use an eight years dataset of highly resolved weather data based on the Heide et al. (2010). Hourly capacity factors for wind and solar energy have been determined based on an eight years dataset (2000-2007) of highly resolved $(50 \mathrm{~km})$ reanalysis data. The aggregation of capacity factors from the $50 \mathrm{~km}$ cells to the 83 European model regions is based on a wind and solar capacity distribution across the 


\begin{tabular}{|c|c|c|c|c|c|c|}
\hline Technology & $\begin{array}{l}\text { Inv. } \\
\text { Costs } \\
€ / \mathrm{kW}_{e l}\end{array}$ & $\begin{array}{l}\text { Fix } \\
\text { O\&M } \\
\text { Costs } \\
€ / \mathrm{kW}_{e l}\end{array}$ & $€ / \mathrm{MWh}_{e l}$ & $\%$ & $a f_{i}$ & $\% / \mathrm{h}$ \\
\hline Bioenergy & 2500 & 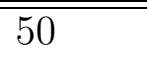 & "18 & $38 \%$ & $40 \%$ & $25 \%$ \\
\hline Coal & 1400 & 35 & 21 & $46 \%$ & $80 \%$ & $22 \%$ \\
\hline Gas GT & 400 & 18 & 68 & $38 \%$ & $100 \%$ & $100 \%$ \\
\hline Gas CCGT & 650 & 18 & 44 & $60 \%$ & $90 \%$ & $22 \%$ \\
\hline Geothermal & 2800 & 80 & 4 & $45 \%$ & $100 \%$ & $25 \%$ \\
\hline Lignite & 2300 & 40 & 13 & $43 \%$ & $80 \%$ & $14 \%$ \\
\hline Oil GT & 800 & 18 & 126 & $35 \%$ & $100 \%$ & $100 \%$ \\
\hline Oil CCGT & 900 & 18 & 89 & $50 \%$ & $90 \%$ & $22 \%$ \\
\hline Nuclear & 3000 & 65 & 12 & $33 \%$ & $80 \%$ & $8 \%$ \\
\hline Hydro run of river & 1400 & 20 & 5 & $75 \%$ & $100 \%$ & $100 \%$ \\
\hline Hydro storage & 1539 & 20 & - & $85 \%$ & $100 \%$ & $100 \%$ \\
\hline $\mathrm{HV}$ lines,$€ / \mathrm{MWkm}$ & 400 & 0.7 & - & $96 \% / 1000 \mathrm{~km}$ & $100 \%$ & $100 \%$ \\
\hline $\mathrm{HV}$ cable,$€ / M W k m$ & 2500 & 0.7 & - & $96 \% / 1000 \mathrm{~km}$ & $100 \%$ & $100 \%$ \\
\hline
\end{tabular}

Table 1: Investment, fixed operation \& maintenance and total variable costs. The variable costs include fuel costs and variable operation \& maintenance costs, but not the carbon costs. For the computation of the annuity of investment, a weighted average cost of capital (WACC) of $7 \%$ is assumed. CCGT stands for Combined Cyle Gas Turbine and GT for Gas Turbine.

$50 \mathrm{~km}$ cells determined in accordance to planned projects, national policies and actual potential. Most recent wind turbine generators and solar photovoltaic cells (PV) are assumed. The hourly load curve for the years 2000 - 2007 stems from the European Transmission System Operator ENTSO-E (ENTSO-E, 2010). We select six representative weeks for each of the eight years database and model 48 (six times eight) weeks in total.

The existing grid infrastructure is obtained from freely available data on the European high voltage $(\mathrm{HV}, 220 \mathrm{kV}$ and $380 \mathrm{kV})$ electricity grid (ENTSO-E, 2010). A Geographic Information System is applied to digitalize the map of the transmission grid and intersect it with the model regions. HV transmis- 
sion lines are commonly operated at their natural load level, where no voltage drop occurs. Therefore we compute the total transmission capacity between model regions based on the natural load of all $\mathrm{HV}$ lines linking two model regions. In dependence on the voltage level, the natural load for each HV line is calculated. The aggregation of all HV lines between two model regions results in the total transmission capacity. Results are shown in Figure 1 .

We built a geo-referenced power plant database to determine the actual generation capacities per model region. The database combines the UDI power plant database (Platts, 2009) and a second data base including energy production, emission and geographic location of each power plant (Wheeler and Ummel, 2008). Coupling these two datasets on power plant level provides a powerful and exhaustive geo-referenced database for Europe. The future power plant fleet is extrapolated with technology specific lifetimes (IEA, 2010b; Öko-Institut, 2008).

In all scenarios in this paper, we assume that the demand remains the same as in 2007. Studies and a constant trend in the last years support this assumption (McKinsey et al., 2010; ENTSO-E, 2009).

We benchmark our model against historical data. The validation shows, that the model reproduces the current European electricity system in adequate accuracy. This is presented in detail in Appendix A.2

\subsection{Scenario Setup}

We apply the model to study the effects of increasing shares of wind and solar energy in Europe in 2020 and the role of transmission grid extensions.

As mentioned above, power plant dispatch, but also infrastructure extension can be determined by the optimization. In this study, VRE ca- 
pacity additions for 2020 are exogenous to the model and drawn from the National Renewable Energy Action Plans of the European Member States (Beurskens and Hekkenberg, 2011). Regional distributions within countries are based on previous studies, political commitments and planned projects (Bofinger et al., 2008; TradeWind, 2009; EWEA, 2008) and shown in Figure 2. The total planned wind capacity of $218 \mathrm{GW}$ is similar to previous studies assumptions: for wind on- and offshore power a total European capacity of 180 GW in 2020 was assumed by EWEA (2008), 150 GW by the IEA, 128-238 GW by OffshoreGrid (2010) and 280 GW by GWEC (2011). For solar PV, 92 GW are projected for 2020. The National Renewable Action Plans exceed the projection of 45 GW Solar PV capacity in 2020 by IEA (2010c), but are roughly in line with the projection of EPIA (2011) of more than $60 \mathrm{GW}$ in 2015.

By 2020, some of the existing conventional power plants will be retired and the technology mix of the necessary power plant additions $\left(C N_{i}(x) \quad \forall i \notin\right.$ $\{V R E$, Storage $\})$ are determined by the cost-optimization for each scenario for the scenario year 2020. For some technologies, such as nuclear power and other renewable power (hydro, bio- and geoenergy), political and geographical limits are taken into account (see Table 2). The model allows to compute cost-optimal transmission grid extensions between model regions. In the scenarios we study different levels of grid extensions. Addition of storage capacity, is not allowed in this study focusing on grid extensions only. We assume, that current storage capacities are installed in 2020, reflecting the limited geographic potential for additional pumped hydro storage capacity. Finally, the power plant dispatch and usage of the transmission grid and 


\begin{tabular}{|c|c|c|c|c|}
\hline Input parameter & Base & No Grid & New Lines & New Cables \\
\hline VRE capacities & $\begin{array}{ll}\text { current ca- } \\
\text { pacities }\end{array}$ & \multicolumn{3}{|c|}{ 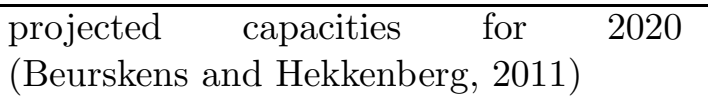 } \\
\hline $\begin{array}{l}\text { Installed non } \\
\text { VRE capacities }\end{array}$ & \multirow{2}{*}{\multicolumn{4}{|c|}{$\begin{array}{l}\text { projected capacities for } 2020 \text { (retirements are taken into } \\
\text { account), current hydro storage and run-of-river capaci- } \\
\text { ties (Platts, } 2009) \\
\text { capacity addition for nuclear, geothermal and bioenergy } \\
\text { are limited to maximum between } 2020 \text { extrapolations and } \\
\text { current capacities, no VRE additions allowed, infinite for } \\
\text { all other generation technology }\end{array}$}} \\
\hline $\begin{array}{l}\text { Limits for ca- } \\
\text { pacity additions }\end{array}$ & & & & \\
\hline $\begin{array}{l}\text { HV transmis- } \\
\text { sion grid }\end{array}$ & $\begin{array}{l}\text { current } \\
\text { ENTSO-E } \\
\text { grid }\end{array}$ & $\begin{array}{l}\text { current } \\
\text { ENTSO-E } \\
\text { grid and } \\
\text { direct con- } \\
\text { nections } \\
\text { of offshore } \\
\text { wind to } \\
\text { shore }\end{array}$ & \begin{tabular}{|l} 
overhead \\
line ex- \\
tensions \\
between \\
neighbors \\
possible. \\
Sea-cables \\
allowed on \\
selected \\
connections
\end{tabular} & $\begin{array}{l}\text { cable ex- } \\
\text { tensions } \\
\text { between } \\
\text { neighbors } \\
\text { possible. } \\
\text { Sea-cables } \\
\text { allowed on } \\
\text { selected } \\
\text { connections }\end{array}$ \\
\hline Carbon price & $30 € / \mathrm{t}$ & $30 € / \mathrm{t}$ & $30 € / \mathrm{t}$ & $30 € / t$ \\
\hline
\end{tabular}

Table 2: Definition of scenarios

existing storage capacities $\left(E_{i}^{\text {out }}(x, t)\right)$ results from the optimization and its boundary conditions, in particular equation 2, 3, and 4.

Table 2 lists the characteristics of the four scenarios. The Base scenario serves as comparison for the VRE scenarios. It mimics the power supply system by 2020 without the projected VRE capacity additions. For the VRE scenarios we investigate three levels of grid extensions: today's network ( $N o$ Grid) and two cases of cost-optimal grid extensions: in the New Lines scenario new overhead lines and offshore cables are allowed, in the New Cables scenarios only cable extensions on- and offshore are possible. Cables are about six times more expensive than overhead lines (see Table 1). The sec- 
ond case therefore results in less grid extensions. The New Cables scenario thus allows to identify the most important grid extension and furthermore represents one possible technical response to public resistance towards new overhead transmission lines.

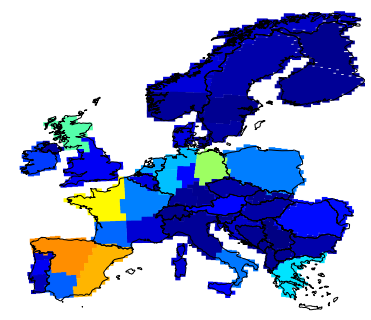

(a) Wind $(152 G W)$
Onshore (b) (66 GW
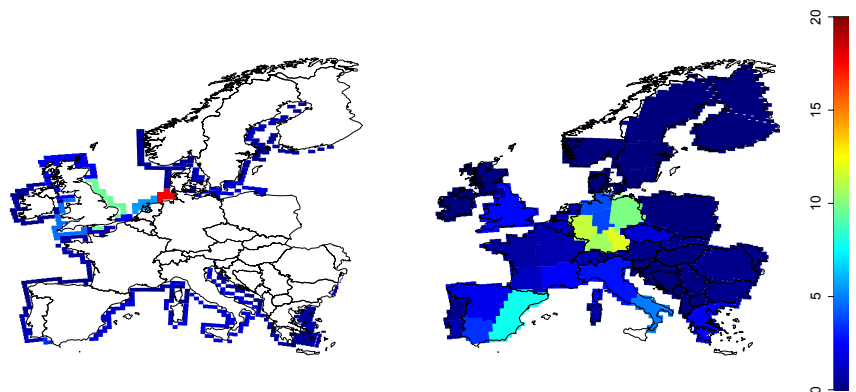

Photovoltaics (92 $G W)$

Figure 2: Capacities of Variable Renewable Energies for 2020 in GW (see Beurskens and Hekkenberg (2011)). Total European capacity per VRE technology is indicated in brackets.

\section{Results: European electricity supply in 2020}

We apply the model URBS-EU to analyze grid extensions as a measure to address economic effects of high VRE penetration in Europe. In a first step we present cost-optimal high voltage transmission grid extensions for Europe in 2020, then turn to the impacts of the planned VRE capacities to the existing power plants and finally study prices and revenues per generation technology and region. 


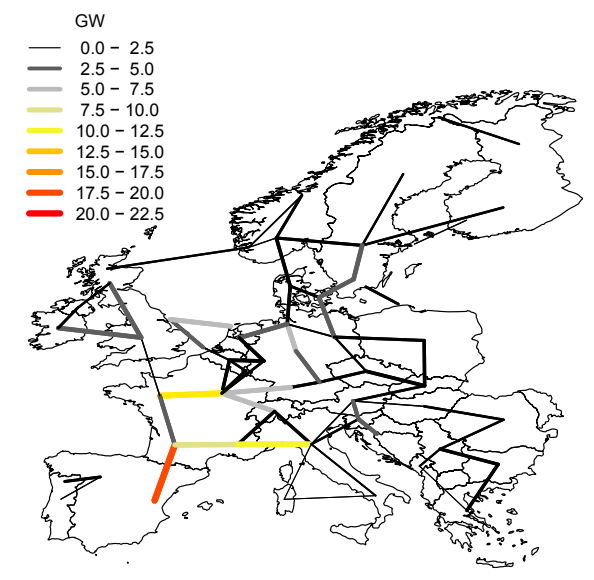

(a) New Lines

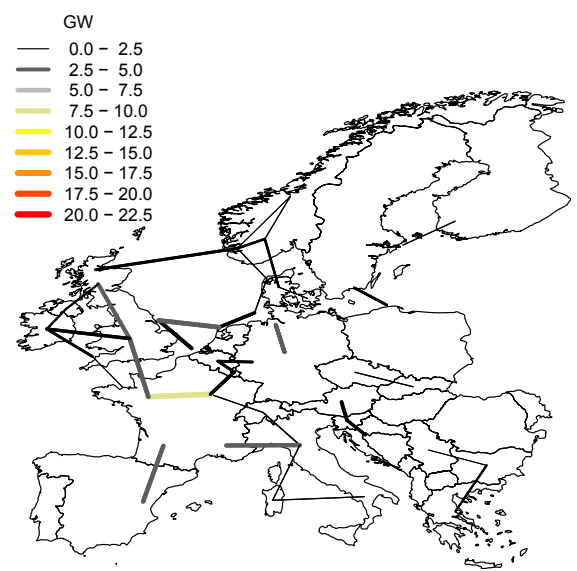

(b) New Cables

Figure 3: Cost optimal grid extensions

The cost-optimal grid extensions in the New Lines and New Cables scenario are depicted in Figure 3. Large transmission capacities result from the optimization model. The total the grid capacity increases by almost $60 \%$ in the New Lines scenario and by more than $20 \%$ in the New Cables scenario compared to the current ENTSO-E grid capacity and length (in MWkm). This is plausible from an economic point of view, since new lines are relatively cheap compared to the additional use of fossil fuel (see Table1). Overhead lines are less expensive than cables (see Table1) and therefore, less grid extensions result in the New Cables scenario. The grid extensions are driven by the VRE capacity addition, but also bear benefits for conventional power plants. 
Germany, France and BeNeLux 1 act as transit countries. In north-western France, northern Germany and Great-Britain substantial grid extensions are cost-effective in both scenarios to integrate the large wind capacities in these areas. Large new grid capacities result for the Spanish-French connection, but only little additions on the Iberian peninsula occur. Italy, having a rather weak electricity grid today, profits from a cost-effective enforcement of its connection to France. Offshore grid extensions are mainly located in the Northern and Baltic Sea, in proximity to important on- and offshore wind capacities. In the New Lines scenario the majority of grid extensions are onshore as lines are cheaper than cables, while in the New Cables scenario larger shares of the grid extensions are offshore cables. We assumed identical costs for on- and offshore cables. In BeNeLux and Italy for instance, offshore grid extensions are more cost-effective than onshore cable extensions in the New Cables scenario. If overhead lines can be built, the bulk power transmission takes place onshore (New Lines).

We find that an offshore grid in the Northern sea is cost-effective, in consistency with other studies. On- and offshore grid extensions for wind integration proposed in TradeWind (2009) and Kerner (2007) show the same corridors as the ones identified in this study. EWEA (2009b) focuses on European offshore wind parks and proposes a powerful interconnected offshore network in the Northern and Baltic Sea. The proposed capacities for 2020 and 2030 by the EWEA are in line with our results. 


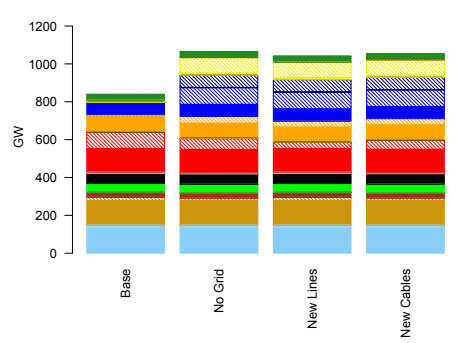

(a) Capacities

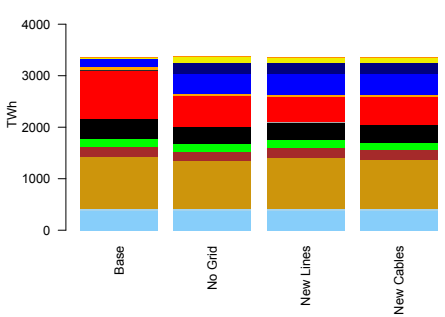

(b) Total Energy Production

Figure 4: Power plant capacities and energy production in 2020 for all scenarios. Shaded areas represent capacity additions.

\subsection{Power Plants}

Figure 4 presents the model results for power plant capacities and energy generation in Europe.

To the $690 \mathrm{GW}$ of the power plants that will still be on line in 2020 , the optimization model adds about 115 GW new capacity in the Base scenario to replace retired power plants and those shut down for political reasons, such as the phase-out of nuclear power in Germany. Capacity additions are represented by shaded areas in Figure 4(a), The additional 234 GW new VRE capacity lead to a slight reduction of conventional capacity additions in the No Grid scenario, where 100 GW non-VRE capacity is added. This corresponds to a capacity credit of the VRE technologies of $4 \%$. With grid extension less new thermal capacity is needed: about $80 \mathrm{GW}$ is added in the New Lines and about $90 \mathrm{GW}$ in the New Cables scenario. The capacity credit

\footnotetext{
${ }^{1}$ including Belgium, the Netherlands and Luxembourg
} 
increases to $14 \%$ and $9 \%$ respectively. In all scenarios, nuclear and gas power plants are the only technologies, where new capacities are added. Compared with the European peak load of 619 GW, the conventional installations are, however, still able to provide full backup for the VREs in all scenarios.

Figure 4(b) shows the model's outputs regarding the energy mix. Since the VREs' share in total electricity production increases from $5 \%$ to $21 \%$ through the VRE capacity additions, the conventional power plants' output is significantly reduced, while conventional capacity remains close to current capacity. The averaged full load hours (FLHs) over all thermal generation types (Coal, Lignite, Gas, Oil, Nuclear and Bio- and Geoenergy) decrease by $9 \%$ in No Grid case.With grid extensions (New Lines) the total average reduction in FLH for thermal generation types amounts $5 \%$ and baseload power, mainly nuclear, replaces peaking technologies such as gas, as can be seen in Figure 4(b)

The reduction in power plant usage is most severe in regions with high VRE deployment and will create severe pressure for the conventional power plant operators. In regions with high VRE capacity, the FLHs of base load power plants such as nuclear and coal generation units decline sharply, if no grid extensions are realized, because they have to adapt to VRE supply (see Figure 5). With an extended, cost optimal grid, more traditional usage of the power plants is possible: baseload power is used more continuously, while the mid and peak load power plants also in the neighboring regions help to balance the VRE fluctuations. These technologies in turn supply less energy in total. 


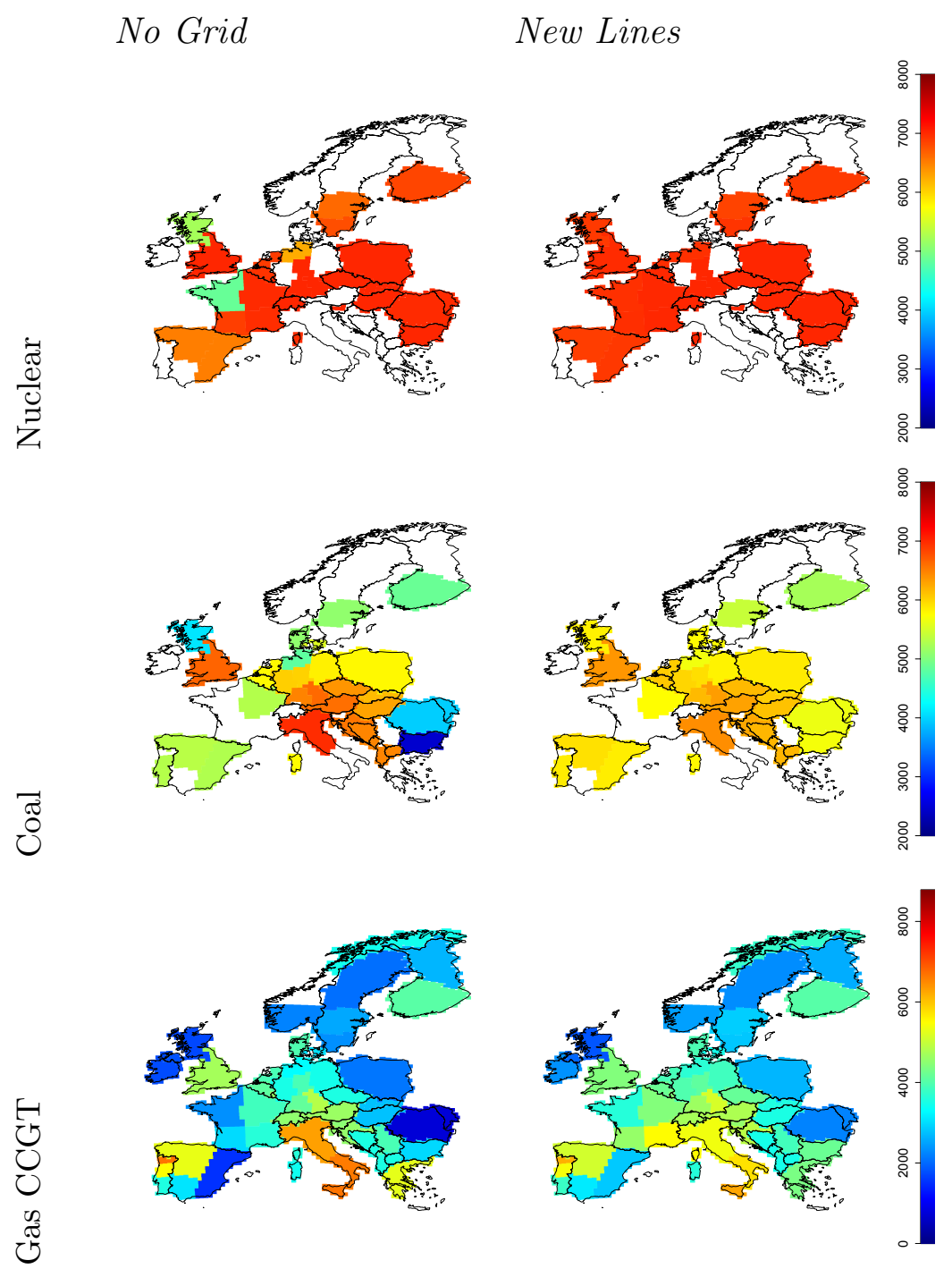

Figure 5: Full Load Hours of nuclear, coal and gas power plants for the No Grid and New Lines scenario

One of the most affected regions by new VRE capacities is north-western Germany. Here, 18 GW offshore wind capacity is projected for 2020, 4 GW of solar PV and $6 \mathrm{GW}$ of wind onshore capacity (see Figure 2). Many important effects of the VRE integration for the power plants can be studied 
in detail from Figure 6, where the computed energy mix and the resulting energy prices for the North-Western German region $D-E O N-N$ are shown for one of the eight modeled meteorological years.

In the Base scenario, the base load is covered by nuclear and coal power plants, gas power plants and also electricity import from neighboring regions provide the mid and peak load. The region exports electricity, as can be read off from the difference between the yellow line, the electricity demand within the region, and the orange total demand line where export and storage charging is included. In the Base scenario, the current onshore wind capacity of $5.3 \mathrm{GW}$ is installed.

In the scenarios No Grid and New Lines, large amounts of additional wind energy from a dedicated offshore region are imported into the considered region, shown as gray areas in Figure 6 (b) and (c). This results in drastic changes in the power plant dispatch, if no grid extensions are carried out (No Grid). In windy hours, wind energy replaces power from peak, middle and also base load power plants. Even nuclear power has to shut down several times. With grid extensions (New Lines), the base load power plants can be used in a more traditional way. The burden of balancing the fluctuating wind energy is then shared between all peak and mid load power plants in the linked neighboring regions.

Also the capacity additions alter slightly across scenarios: in the Base case slightly more new Gas CCGT capacity $(1.3 \mathrm{GW})$ is installed. 

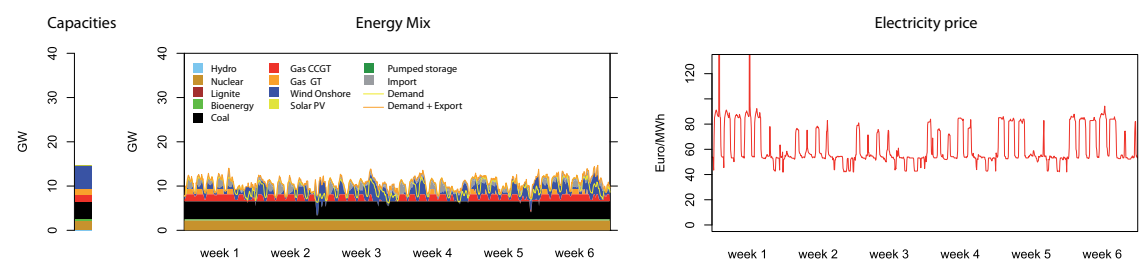

(a) Base
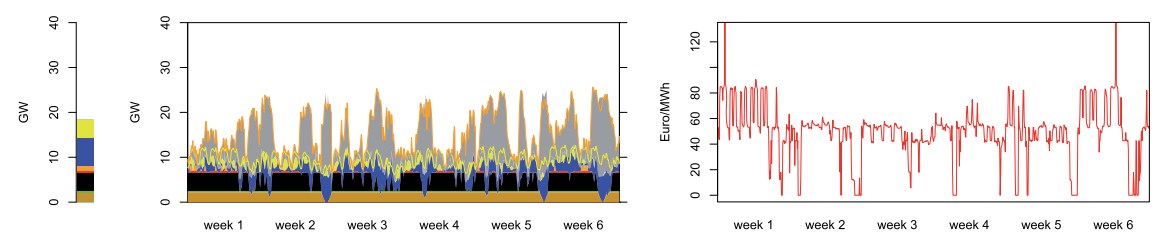

(b) No Grid
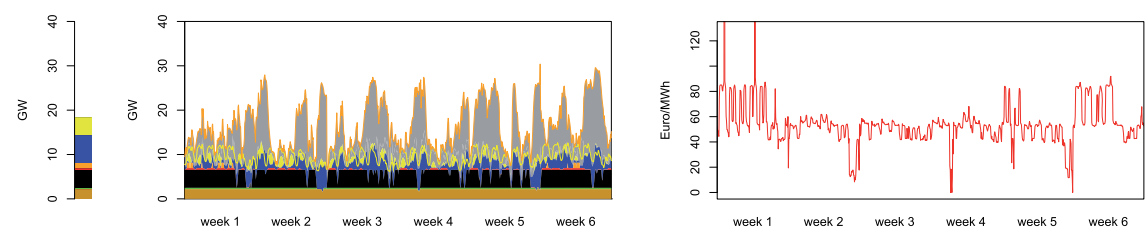

(c) New Lines

Figure 6: Energy mix in north western Germany $(D-E O N-N)$ and electricity price for selected weeks in 2020 (meteorological data from 2003).

\subsection{Electricity prices and revenues}

Not only power plant dispatch changes considerably with VRE capacity, also the electricity prices are strongly influenced.

This can be seen for north western Germany in Figure6, Power supply from VRE strongly influences electricity prices. Their variable costs are close to zero and thus, wind power enters at the first position in the merit order of power plants. Whenever wind and solar energy supply is sufficient to satisfy the demand, the price drops to zero and through the merit order effect, the electricity price in regions with high VRE capacity is lowered. As mentioned in Section 3, negative prices are not taken into account. 
Figure 7 shows the average electricity price for the four scenarios. The average electricity price in Europe is $62 € / \mathrm{MWh}$ in the Base scenario. In the No Grid it drops to $52 € / \mathrm{MWh}, 17 \%$ lower than the basecase. With grid extensions the average price recovers to $55 € / \mathrm{MWh}$ and $53 € / \mathrm{MWh}$ with new lines or cables respectively. As can be seen from the maps, regions with high VRE capacity are most affected by the reductions in electricity price. In north-western Germany, the average price drops from $65 € / \mathrm{MWh}$ to $50 € /$ MWh with 2020 VRE capacity additions and no grid extensions (see also Figure 6). Generally speaking, the standard deviation of electricity price across regions increases with increasing VRE capacity. In the Base case the standard deviation of elecricity prices across the European regions amounts $5 € /$ MWh. It increases to $8 € / M W h$ and can be lowered with grid extensions to 3 and $6 € /$ MWh respectively. Grid extensions lead to a homogenization of the electricity prices. 


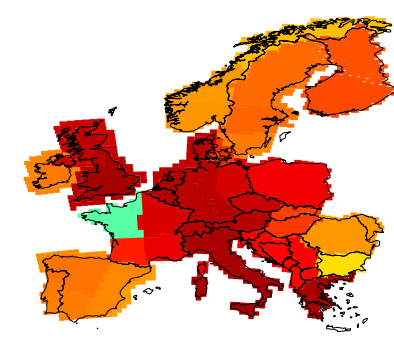

New Lines

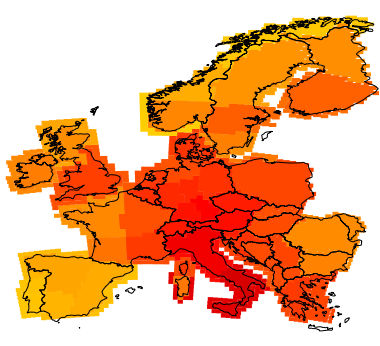

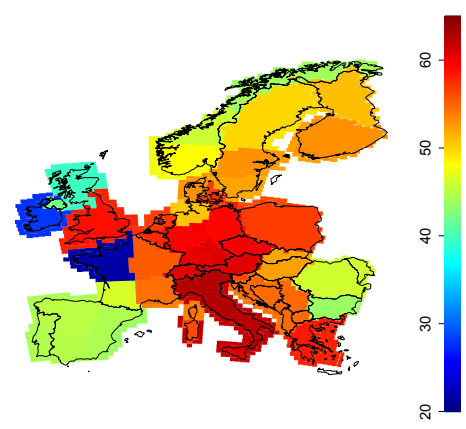

New Cables

Figure 7: Average electricity price $\left(€ / \mathrm{MWh}_{e l}\right)$

Furthermore, the dynamics of the prices changes. While in the current system and in the Base case, the electricity price is mainly determined by the load (see Figure 6), the average correlation between load and prices drops to around $25 \%$ in the 2020 VRE scenarios from $75 \%$ today. In turn, generation from wind turbines plays an increasingly important role for electricity prices. In regions with high VRE capacity strong anticorrelation between wind generation and electricity prices can be observed, see Table 3, Solar power generation is generally smaller and also closer to the load. Therefore, its effects to the electricity price are not yet as pronounced. Grid extensions reduce the anticorrelation between wind and price. With grid extensions, the 
anticorrelation is reduced by about $50 \%$ in affected regions (see Table 3).

\begin{tabular}{l|ccc}
$\begin{array}{l}\text { Correlation } \\
\text { price and wind }\end{array}$ & Spain NW & Scotland & Germany NW \\
\hline No Grid & $-61 \%$ & $-50 \%$ & $-32 \%$ \\
New Lines & $-28 \%$ & $-20 \%$ & $-16 \%$ \\
New Cables & $-58 \%$ & $-36 \%$ & $-17 \%$ \\
Wind capacity & 18 & 11 & 23 \\
(GW) & & &
\end{tabular}

Table 3: Correlation between electricity price and generation from wind energy in selected regions. The last row lists the total on- and offshore wind capacity in the regions.

The changes in electricity prices and FLHs affect the revenues of the utilities. Figure 8 shows the average annual revenue per installed MW for each generation technology. All technologies are affected and achieve lower revenues. Note, that Figure 8 shows the average revenues per technology. New power plants will be used more frequently, due to higher efficiency and resulting lower variable costs. They may thus achieve higher revenues. However, for some peaking technologies, the benefit is small and balancing markets have to be used as well. Stagnant investment in new power plants before the economic crisis reflects the difficulties at the market (Dena, 2008). Without grid extensions for the new VRE capacity (No Grid), the standard deviation of the revenue across regions increases due to the inhomogeneous distribution of VRE capacities in 2020. The profitability of conventional power plants will be strongly influenced by the amount of VRE capacity close by.

Network improvements lead to more uniform prices in time and space. They reduce the standard deviation of the revenues across the regions significantly. VREs are affected very positively by grid extensions since fewer low price situations occur. As large VRE generation mainly causes the low prices, these 


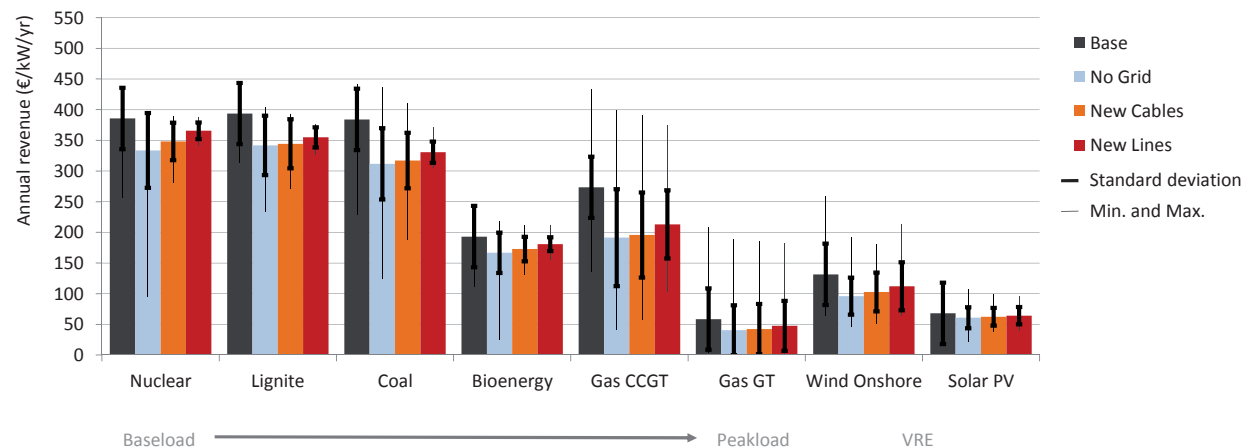

Figure 8: Revenues per generation technology for the four scenarios. Standard deviation and minimal and maximal values across the model regions are indicated with the black lines.

technologies can hardly earn important revenue in the current market structure (Neuhoff, 2005). Grid extensions smoothen the electricity price. As a result, less low price events occur and the revenues for VRE increases. Baseload power plants such as nuclear, coal and lignite also benefit substantially from grid extensions. The average revenues reach current levels if cost-optimal overhead transmission extensions are realized. For mid and peak-load power plants, the economic situation remains difficult even with large grid extensions, due to important FLH reductions.

Figure 9 shows the change in revenue due to VRE additions by country. Regions with largest additions are most affected, as for example Germany, Spain, France and Great Britain, where the revenues for nuclear power are reduced by up to $25 \%$. Looking in more detail, in north-western France and in Scotland, revenue for nuclear reach is reduced by more than $50 \%$ from the Base to the No Grid scenario. As pointed out before, VREs are most affected if they participated in the electricity market directly. For Gas CCGT 
power plants, a mid and peak load technology, grid extensions show only

little effect and the revenue remains low. In importing regions, such as Italy, grid extensions can even lead to an additional decrease revenue.

In general, transmission grid extensions reduce the future revenue reduction from VRE and distribute the economic surpluses evenly across interconnected regions.
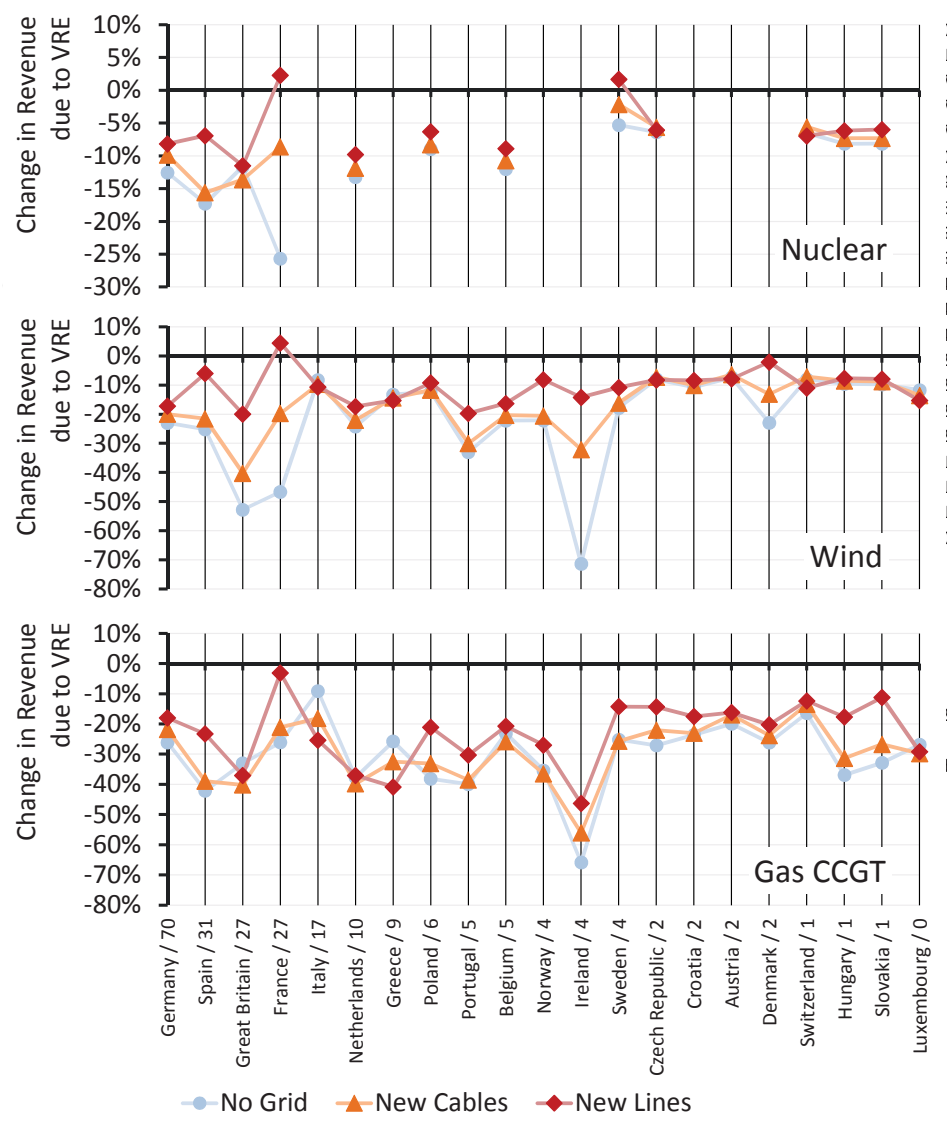

Figure 9: Relative change in revenue with VRE additions compared to Base. The countries are plotted in decreasing order of VRE capacity additions. After the country names VRE additions until 2020 are indicated in GW. 


\section{Discussion}

In this study we apply a regionally-resolved, power system model to analyze the role of grid extensions for the interaction of wind and solar energy with electricity markets in Europe. Our results show, that the expected VRE extensions for 2020 have significant impact on electricity markets and their participants. Wholesale electricity prices decrease on average, their variance in time and space increases, and they are dynamically correlated with VRE supply rather than with power demand. Transmission grid extension can help to reduce the market effects of VREs, and moreover creates benefits for other generation technologies.

We investigate two levels of grid extensions, where in a first stage we allow overhead grid extensions between all neighboring regions. The costoptimal grid additions amount $60 \%$ of current grid capacity and length. In a second scenarios, taking into account public acceptance and political challenges, only cable additions are allowed, and a $20 \%$ increase in grid capacity results.

Regardless of the level of grid extensions, the VRE additions projected for 2020 have severe consequences for all other power plant types. Due to the limited capacity credit of wind and solar power, conventional generation capacity is hardly reduced as compared to current level, while the share of VRE in total electricity generation increases from $5 \%$ to $21 \%$. This results in a reduction of FLHs for all conventional generation technologies.

Without grid extensions, very high FLH reductions occur in proximity to important VRE capacities. Through the merit order effect, VREs furthermore 
lower the average simulated electricity prices by more than $15 \%$ in 2020 . Utility owners will face drastic FLH reduction and higher wearout of their turbines due to increased ramping if wind or solar capacity is built close by. The oversupply of electricity in regions with large VRE capacity and insufficient transmission capacity furthermore lowers the electricity price drastically in these regions. In the current market structure, conventional power plants will therefore face serious economic challenges. In regions with large VRE capacities, the reduction in revenue for conventional base, mid and peak load power plants can reach $60 \%$. The average revenue for baseload technologies is reduced by about 15\%, for peakload by 30\%. VRE capacities in 2020 thus create major inequalities in Europe, if no grid capacity additions are carried out simultaneously.

Our results concerning the electricity price reduction are on the conservative side, as we do not take into account negative prices in our model. If negative prices were included, the average prices would be lower. In periods and regions with negative prices it would furthermore become beneficial to shut down power plants, even VRE technologies.

With grid extensions, the average utilization of baseload technologies is raised again and less ramping of baseload technologies is necessary, as the balancing of VRE supply is shared between more flexible power plants in the interconnected regions. Furthermore, the burden of reduced revenues for conventional power plants due to VRE extensions is distributed more evenly among all regions. Both levels of simulated grid extensions boost the revenue for baseload and VRE technologies. Revenues close to pre-VRE levels can 
however only be attained with a substantial grid growth of $60 \%$. For mid- and peakload power plants, average revenues remain low. For VRE technologies themselves the anti-correlation between electricity prices and VRE generation creates a large incentive for grid extensions, if market participation of these technologies is desired. Grid extensions reduce the anti-correlation of prices with VRE generation and thus raises the revenue for VRE technologies.

As a result, grid extensions are economically very advantageous for baseload and VRE utility owners - a rather unlike pair. In the overall picture, a powerful international transmission grid thus bears many advantages. It lowers overall system costs (we derive grid extensions it through cost-optimization), it facilitates the technical and economic integration for VRE technologies and furthermore bears benefits for conventional power plants, mainly for baseload power plants in regions with high VRE deployment.

However, regions with low VRE capacity experience lower electricity prices and potentially lower revenues through grid extension. Mid and peak load utility owners in those regions might not want to share the burden of VRE integration with neighboring regions as this results in increased ramping, lower FLHs and lower electricity prices. Therefore the political challenge of international electricity market coupling will increase with increasing VRE capacities. While today, existing infrastructure mainly determines international trade flows, e.g., export of nuclear power from France to Italy, different trade flows, highly determined by VRE capacity, will occur in 2020. The importing region will still have to provide sufficient capacity to ensure security of supply, which in turn has lower utilization and revenue, because the neigh- 
boring country installs large VRE capacity and exports parts of its electricity generation. Increased coordination of the dispatch of interlinked regions and also of the national requirements for security of supply to reduce the disadvantages for the importing region.

As mentioned above, electricity prices show a change in dynamics with increasing VRE capacity: they are no longer correlated to electricity demand, but driven by wind generation. With grid extensions, furthermore electricity trades will influence the price level. The more complex dynamics of electricity market will be challenging for market participants. When linking a region with large VRE deployment to one without, the exporting region generally profits from a reduction of complexity in price drivers and in the European overall picture, a smoother and geographically more homogeneous electricity price results, but the importing regions can face an increase in market complexity. Low nodal electricity prices can create incentives for more flexible demand, which can be realized by demand side management, smart grid applications or storage.

Grid extensions for the integration of VREs in Europe bears many benefits, for VRE technologies themselves, but also for other power plants in proximity to VRE capacities. It is not only necessary for the technical integration of VREs, i.e., the transport of electricity from renewable generation to load centers, but also for the economic integration. Revenues for conventional power plant owners are lowered substantially without sufficient grid extensions. However, successful planning of transmission grid extensions for VREs should address potential difficulties for market participants mainly in 
importing regions in addition to existing political challenges.

\section{Conclusion}

Based on a power system model we have analyzed the role of grid extensions for the market effects of VRE. Our model of the European power system is a regionally resolved model and based on linear optimization of overall costs. We benchmarked our model with historical data to fortify our analysis.

Our modeling approach includes several simplifications, of which the assumption of a pan-European electricity market with nodal pricing policy is most relevant to our results. In reality national markets form only one price in each country, which however is strongly influenced by the region with the lowest marginal costs (Ockenfels et al., 2008). However, the model benchmark shows, that our approach reproduces historical electricity prices. We furthermore approximate power plant dispatch with linear functions and aggregate capacity in larger regions. However, the most relevant technical constraints, such as ramping constraints, are included in the model and again, the validation shows adequate consistency of model results with historical data. The model's predictions can thus be taken as a good indicator for future developments of the interlinked European power generation system.

Our results show that expected VRE capacities for 2020 create important inequalities among power plant owners in Europe. Close to VRE generation, lower utilization and electricity prices lead to reduced revenues. Through 
grid extensions, the market effects of VREs are reduced and benefits can be created for other power plants, mainly baseload technologies, through more homogeneous and stable electricity prices and larger revenues. For importing regions and mid to peak load technologies disadvantages can occur through grid extensions.

Our analysis does not include the control power market nor the role of storage in combination with grid extensions. Coming studies may focus on the role of the control power and other system services and tools for the security of supply, which will gain increasing importance in a future with highly renewable electricity supply. Moreover, it would be interesting study the combined effects of grid and storage for VRE market effects.

\section{Appendix A.}

\section{Appendix A.1. Model formulation}

For detailled understanding, we list the fundamental equations defining the power system model URBS-EU in this section. The list of symbols is provided in Table A.4.

The objective function, i.e., the total costs subject to minimization are

$$
\begin{aligned}
K & =K_{I_{G}}+K_{I_{S}}+K_{I_{T}} \\
K_{I_{G}} & =\sum_{x, i \in I_{G}}\left\{\kappa_{i}^{I} C N_{i}(x)+\kappa_{i}^{F} C_{i}(x)+\kappa_{i}^{V} \sum_{t} E_{i}^{o u t}(x, t)\right\} \\
K_{I_{T}} & =\sum_{x, i \in I_{T}, x^{\prime} \in N}\left\{r\left(x, x^{\prime}\right)\left[\kappa_{i}^{I} C N_{i}^{T}\left(x, x^{\prime}\right)+\kappa_{i}^{F} C_{i}^{T}\left(x, x^{\prime}\right)+\kappa_{i}^{V} \sum_{t} F_{i}^{i m p}\left(x, x^{\prime}, t\right)\right]\right\} \\
K_{I_{S}} & =\sum_{x, i \in I_{S}}\left\{\kappa_{i}^{I} C N_{i}^{S}(x)+\kappa_{i}^{F} C_{i}^{S}(x)+\kappa_{i}^{V} \sum_{t} V_{i}(x, t)\right\}
\end{aligned}
$$


The most important restriction is the satisfaction of demand. All restrictions are valid $\forall x$ and $\forall t$, if not indicated differently.

$$
d(x, t) \leq \sum_{i} E_{i}^{o u t}(x, t)-\sum_{i \in I_{S} \cup I_{T}} E_{i}^{\text {in }}(x, t)
$$

The following equations control the generation processes.

$$
\begin{aligned}
E_{i}^{\text {out }}(x, t) \leq a f_{i} \cdot C_{i}(x) & \forall i \in I_{G} \\
E_{i}^{\text {out }}(x, t)=c f_{i}(x, t) \cdot a f_{i} \cdot C_{i}(x) & \forall i \in I_{R} \\
p c_{i} \cdot C_{i}(x) \geq\left|E_{i}^{\text {out }}(x, t)-E_{i}^{\text {out }}(x, t-1)\right| & \forall i \in I_{G} \\
C_{i}(x)=c_{i}^{0}(x)+C N_{i}(x) & \forall i \in I_{G} \\
c_{i}^{\text {min }}(x) \leq C_{i}(x) \leq c_{i}^{\text {max }}(x) & \forall i \in I_{G}
\end{aligned}
$$

Power transmission is modelled as a transport problem. All equation are 620 valid $\forall x, t, \forall x^{\prime} \in N, \forall i \in I_{T}$.

$$
\begin{array}{r}
F_{i}^{i m p}\left(x, x^{\prime}, t\right) \leq C_{i}^{T}\left(x, x^{\prime}\right) \\
F_{i}^{i m p}\left(x, x^{\prime}, t\right)=F_{i}^{e x p}\left(x^{\prime}, x, t\right) \cdot \lambda_{i}\left(1-r\left(x, x^{\prime}\right)\right) \\
E_{i}^{\text {out }, \text { in }}(x, t)=\sum_{x^{\prime} \in N} F_{i}^{\text {imp }, \text { exp }}\left(x, x^{\prime}, t\right) \\
C_{i}^{T}\left(x, x^{\prime}\right)=c_{i}^{T, 0}\left(x, x^{\prime}\right)+C N_{i}^{T}\left(x, x^{\prime}\right) \\
c_{i}^{T, \min }\left(x, x^{\prime}\right) \leq C_{i}^{T}\left(x, x^{\prime}\right) \leq c_{i}^{T, \max }\left(x, x^{\prime}\right)
\end{array}
$$

${ }_{621}$ Storage is described by the following equations, valid $\forall x, t, \forall i \in I_{S}$.

$$
V_{i}(x, t) \leq C_{i}^{S}(x)
$$




$$
\begin{array}{r}
E_{i}^{\text {in }}(x, t) \leq a f_{i} \cdot C_{i}(x) \\
c_{i}^{S, \text { min }}(x) \leq C_{i}^{S}(x) \leq c_{i}^{S, \max }(x) \\
C_{i}^{S}(x)=c_{i}^{S, 0}(x)+C N_{i}^{S}(x) \\
E_{i}^{\text {out }}(x, t) \leq V_{i}(x, t) \cdot \eta_{i}^{\text {out }} \\
V_{i}(x, t)=V_{i}(x, t-1)+E_{i}^{\text {in }}(x, t) \cdot \eta_{i}^{\text {in }}-E_{i}^{\text {out }}(x, t) / \eta_{i}^{\text {out }} \quad \forall t>0
\end{array}
$$




\begin{tabular}{|c|c|c|}
\hline \multicolumn{2}{|l|}{ Symbol } & Explanation \\
\hline \multicolumn{3}{|l|}{ Sets } \\
\hline \multicolumn{2}{|l|}{$\begin{array}{l}i \in I=I_{G} \cup I_{T} \\
I_{G}=I_{R} \cup I_{D} \cup I_{S}\end{array}$} & Process type (generation and transmission) \\
\hline \multicolumn{2}{|l|}{ 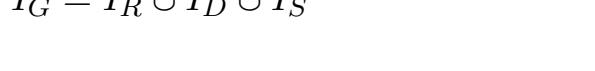 } & $\begin{array}{l}\text { Generation processes (renewables (VREs), dis- } \\
\text { patchable and storage) }\end{array}$ \\
\hline \multicolumn{2}{|l|}{$x \in X$} & Model regions \\
\hline \multicolumn{2}{|c|}{$N=\left\{x^{\prime} \mid \exists x \in X: z\left(x, x^{\prime}\right)=1\right\}$} & Set of neighbors \\
\hline \multicolumn{2}{|c|}{$t \in T$} & Time steps \\
\hline Variables & Domain & Note: all variables are positive \\
\hline$C_{i}(x)$ & $X \times I_{G}$ & Power plant and storage in- and output capacity \\
\hline$C_{i}^{S}(x)$ & $X \times I_{S}$ & Storage reservoir capacity \\
\hline$C_{i}^{T}\left(x, x^{\prime}\right)$ & $X \times I_{T}$ & Grid capacity between region $x$ and $x^{\prime}$ \\
\hline$C N_{i}^{(T, S)}(x)$ & $X \times I_{G}, I_{S}, I_{T}$ & Capacity additions \\
\hline$E_{i}^{\text {out }}(x, t)$ & $X \times T \times I$ & Electricity production \\
\hline$E_{i}^{i n}(x, t)$ & $X \times T \times\left(I_{S} \cup I_{T}\right)$ & Input into storage, sum of exports \\
\hline$F_{i}^{i m p, e x p}\left(x, x^{\prime}, t\right)$ & $X \times N \times T \times I_{T}$ & Power import/export from region $x$ to $x^{\prime}$ \\
\hline$V_{i}(x, t)$ & $X \times T \times I_{S}$ & Stored energy \\
\hline$K, K_{I_{G}}, K_{I_{S}}, K_{I_{T}}$ & & Costs \\
\hline Parameters & Domain & \\
\hline$d(x, t)$ & $X \times T$ & Electricity demand \\
\hline$c f_{i}(x, t)$ & $X \times T \times I_{G}$ & Capacity factor \\
\hline$c_{i}^{0, \min , \max }(x)$ & $X \times I_{G}$ & $\begin{array}{l}\text { Installed, minimal and maximal capacity for } \\
\text { power plants and storage in- and output }\end{array}$ \\
\hline$c_{i}^{S, 0, \min , \max }(x)$ & $X \times I_{S}$ & $\begin{array}{l}\text { Installed, minimal and maximal capacity for stor- } \\
\text { age reservoir }\end{array}$ \\
\hline$c_{i}^{T, 0, \min , \max }\left(x, x^{\prime}\right)$ & $X \times I_{T}$ & Installed, minimal and maximal capacity for grid \\
\hline$z\left(x, x^{\prime}\right)$ & $X \times N$ & Adjacency matrix \\
\hline$r\left(x, x^{\prime}\right)$ & $X \times N$ & Distance between two model regions \\
\hline$a f_{i}, p c_{i}, \eta_{i}$ & $I_{G}$ & availability, maximal power change, efficiency \\
\hline$\lambda_{i}, \eta_{i}^{\text {in,out }}$ & $I_{T}, I_{S}$ & $\begin{array}{l}\text { transmission losses, storage in- and output effi- } \\
\text { ciency }\end{array}$ \\
\hline$\kappa_{i}^{I}, \kappa_{i}^{F}, \kappa_{i}^{V}$ & $I$ & Annuity of investment, fix and variable costs \\
\hline
\end{tabular}

Table A.4: List of symbols 


\section{Appendix A.2. Model validation}

To validate the model's ability to reproduce the real power system, we perform a simulation of the European electricity system of 2008, the most recent year of complete available data before economic crisis. In this so-called Base 2008 scenario no capacity extensions for grid, power plants or storage are allowed and current costs are assumed as shown in Table 1 with a carbon price of $15 € / \mathrm{t}$. We simulate 48 weeks in total: six representative weeks of each of the eight year of available meteorological data.

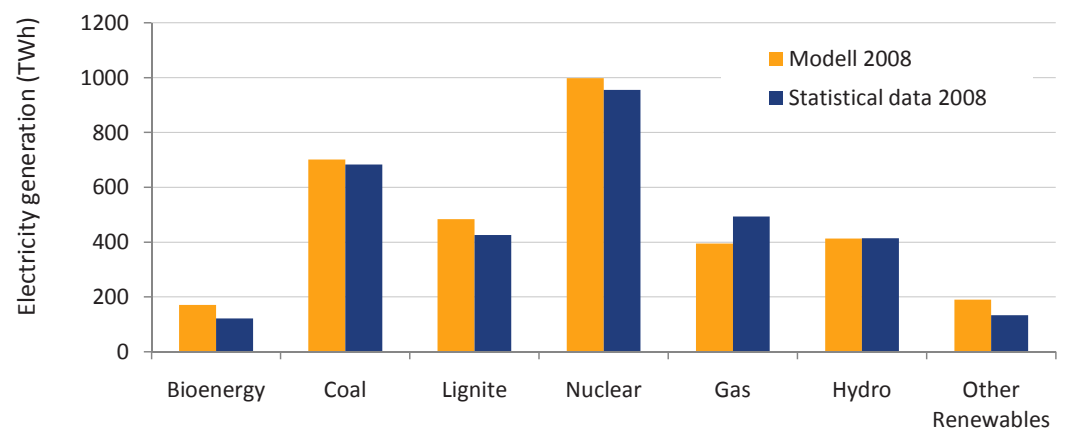

Figure A.10: Comparison of modeled electricity production in Europe to measured data (IEA, 2010a).

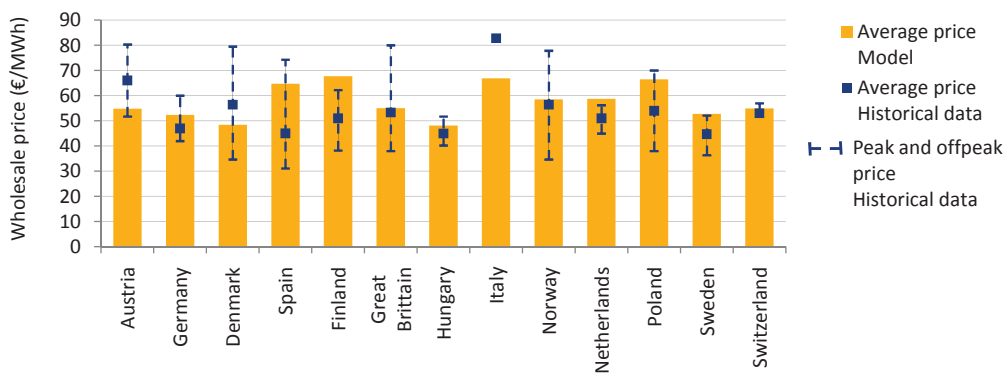

Figure A.11: Comparison of the average electricity prices in Europe (Bower, 2003; OMEL, 2010; EXAA, 2010; EEX, 2009; NordPool, 2010) with the modelled average marginal costs of electricity generation 
Figure A.10 compares the total European electricity generation by fuel resulting from the model to historical data (IEA, 2010a). We observe a good fit of the produced power for the base load plants (coal, lignite, nuclear and hydro). The model slightly underestimates the power production of peak load power plants (gas). This is due to the deterministic nature of the optimization model. Unforeseen outages of power plants and forecast errors are not included in the model, while peak load power plants are often used exactly to counter balance these events.

Wholesale electricity prices are deduced from the marginal costs of electricity generation and are consistent with historical average wholesale prices (see Figure A.11). The model furthermore reproduces extreme values of the electricity price and the computed price shows $70 \%$ correlation with the historical day ahead market prices for Germany (EEX, 2009).

Modeled cross-boarder electricity exchange is similar to historical data as shown Figure A.12. One reason for remaining deviations might be a non costoptimal cross-border scheduling in reality, as well as our simplified methodology to model power transport.

The reproduction of historical data with the model is robust against changes in fuel prices. A considerable increase of fuel prices (20\% for gas, $40 \%$ for coal, $120 \%$ for nuclear variable costs) has no major impacts on the model benchmark. 


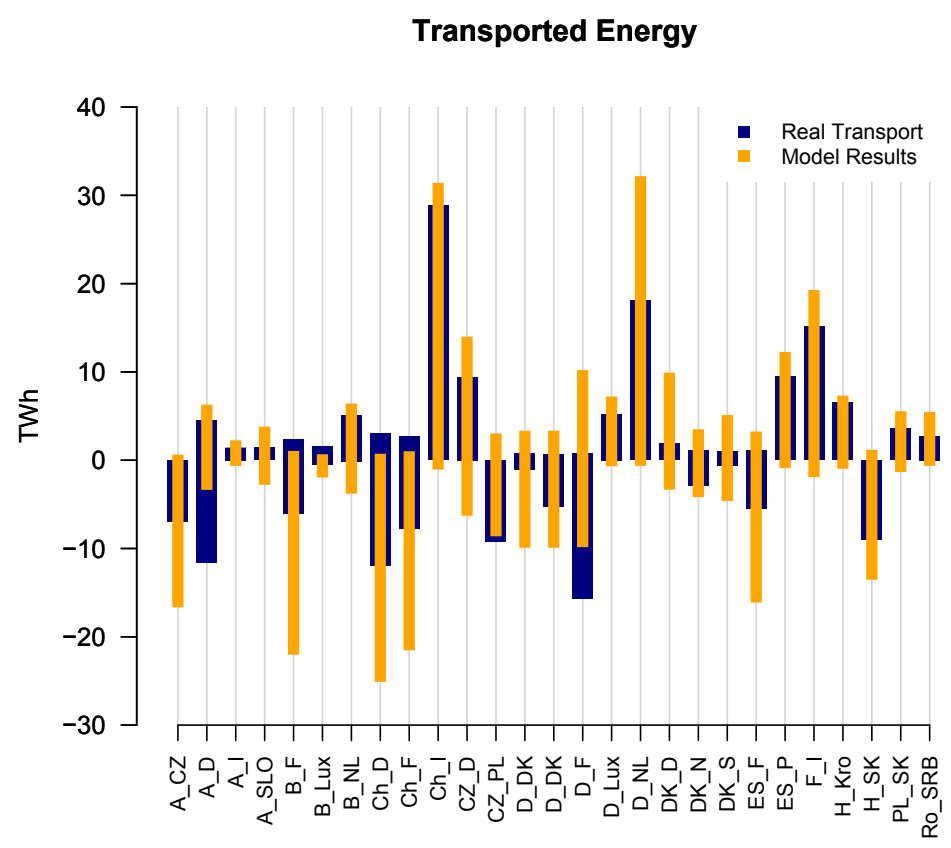

Figure A.12: Cross-boarder electricity exchange: model results (Base 2008) and historical data (ENTSO-E, 2010)

Aboumahboub, T., 2011. Development and Application of a Global Electricity System Optimization Model with a Particular Focus on Fluctuating Renewable Energy Sources. Ph.D. thesis, Lehrstuhl für Energiewirtschaft und Anwendungstechnik, Technical University Munich, Prof. U. Wagner.

Beurskens, F., Hekkenberg, M., 2011. Renewable Energy Projections as Published in the National Renewable Energy Action Plans of the European Member States Covering all 27 EU Member States. European Environment Agency. 
URL

http://www.ecn.nl/units/ps/themes/renewable-energy/ projects/nreap/

Biberacher, M., 2004. Modeling and optimization of future energy system using spacial and temporal methods. Ph.D. thesis, Institute of Physics, University of Augsburg.

BMU, 2011. Bundesministerium für Umwelt, Naturschutz und Reaktorsicherheit: Erneuerbare Energien in Zahlen. BMU, Berlin.

URL http://www.bmu.de/files/pdfs/allgemein/application/pdf/ ee_in_zahlen_2010_bf.pdf

Bofinger, S., von Bremen, L., Knorr, K., Lesch, K., Rohrig, K., SaintDrenan, Y.-M., Speckmann, M., 2008. Raum-zeitliche Erzeugungsmuster von Wind- und Solarenergie in der UCTE-Region und deren Einfluss auf elektrische Transportnetze: Abschlussbericht für Siemens Zentraler Forschungsbereich (Temporal and spatial generation patterns of wind and solar energy in the UCTE region. Impacts of these on the electricity transmission grid). Institut für Solare Energieversorgungstechnik, ISET e.V., Kassel.

Borchert, J., Schemm, R., Korth, S., 2006. Stromhandel: Institutionen, Marktmodelle, Pricing und Risikomanagement. Schäffer-Poeschel, Stuttgart.

URL http://deposit.ddb.de/cgi-bin/dokserv?id=2803439\& prov=M\&dok_var=1\&dok_ext=htm/http://www.gbv.de/dms/bsz/toc/ bsz25421794xinh.pdf 
Bower, J., 2003. A review of european electricity statistics.

URL http://www . oxfordenergy.org/pdfs/jelsample.pdf

Czisch, G., 2005. Szenarien zur zukünftigen Stromversorgung, Kostenoptimierte Variationen zur Versorgung Europas und seiner Nachbarn mit Strom aus erneuerbaren Energien (Scenarios for a future power supply, cost optimal scenarios for renewable power supply in Europe and its neighbors). Ph.D. thesis, Elektrotechnik / Informatik der Universität Kassel.

de Miera, G. S., del Rio Gonzalez, P., Vizcaíno, I., 2008. Analysing the impact of renewable electricity support schemes on power prices: The case of wind electricity in spain. Energy Policy 36 (9), 3345 - 3359.

Dena, 2005. Deutsche Energie-Agentur GmbH: Energiewirtschaftliche Planung für die Netzintegration von Windenergie in Deutschland an Land und Offshore bis zum Jahr 2020, Endbericht (Energy economic planning of grid integration for wind on- and offshore energy in Germany until 2020).

URL http://www.dena.de/de/themen/thema-esd/publikationen/ publikation/netzstudie/

Dena, 2008. Deutsche Energie-Agentur GmbH: Kurzanalyse der Kraftwerksund Netzplanung in Deutschland bis 2020 (mit Ausblick auf 2030). URL http://www.dena.de/themen/thema-esd/projekte/projekt/ kraftwerks-und-netzplanung/

Dena, 2010. Deutsche Energie-Agentur GmbH: dena-Netzstudie II: Integration enerneuerbarer Energien in die deutsche Stromversorgung im 
Zeitraum 2015-2020 mit Ausblick 2025.

URL http://www.dena.de/themen/thema-esd/projekte/projekt/ dena-netzstudie-ii

DLR, 2006. Trans-Mediterranean Interconnection for Concentrating Solar Power (TRANS-CSP), Final Report, Study by German Aerospace Center (DLR), Institute of Technical Thermodynamics, Section Systems Analysis and Technology Assessment and the Federal Ministry for the Environment, Nature Conservation and Nuclear Safety, Germany.

URL http://www.dlr.de/tt/desktopdefault.aspx/tabid-2885/ 4422_read-6588/

Edenhofer, O., Knopf, B., Barker, T., Baumstark, L., Bellevrat, E., Chateau, B., Criqui, P., Isaac, M., Kitous, A., Kypreos, S., Leimbach, M., Lessmann, K., Magné, B., Scrieciu, S., Turton, H., Vuuren, D. v., 2010. The Economics of Low Stabilization: Model Comparison of Mitigation Strategies and Costs. Energy Journal 31.

EEX, 2009. European Energy Exchange: German Day-Ahead Electricity Market.

URL www.eex.com

ENTSO-E, 2009. System Adequacy Retrospect. European Network of Transmission System Operators.

ENTSO-E, 2010. European Network of Transmission System Operators for Electricity: Statistical Data.

URL https://www.entsoe.eu/ 
EPIA, 2009. European Photovoltaic Industry Association \& A.T. Kearney: Set for Sun.

URL http://www.setfor2020.eu/

EPIA (Ed.), 2011. European Photovoltaic Industry Association: Global Market Outlook for Photovoltaics until 2015. EPIA.

EU Commission, 2006. Commission of the European Communities: Renewable Energy Road Map: Renewable Energies in the 21st century: building a more sustainable future. Communication from the Commission to the Council and the European Parliament 848.

EWEA, 2008. European Wind Energy Association: Pure Power - Wind Energy Scenarios up to 2030.

URL http://www.ewea.org/fileadmin/ewea_documents/documents/ publications/reports/purepower.pdf

EWEA, 2009a. European Wind Energy Association: A breath of fresh air, Annual Report.

URL http://www.ewea.org/fileadmin/ewea_documents/documents/ publications/reports/Ewea_Annual_Report_2009.pdf

EWEA, 2009b. European Wind Energy Association: Oceans of Opportunity: Harnessing Europe's largest domestic energy resource.

URL http://www.ewea.org/fileadmin/ewea_documents/documents/ publications/reports/Offshore_Report_2009.pdf

EXAA, 2010. Energy exchange austria.

URL www.exaa.at 
Giebel, G., 2000. On the Benefits of Distributed Generation of Wind Energy in Europe. Ph.D. thesis, Fachbereich Physik der Universität Oldenburg.

Green, R., Vasilakos, N., 2010. Market behaviour with large amounts of intermittent generation. Energy Policy 38 (7), 3211 - 3220.

Greenpeace, 3E, 2008. A North Sea electricity grid [r] evolution: electricity output of interconnected offshore wind power: a vision of offshore wind power integration.

URL http://www.greenpeace.org/raw/content/eu-unit/ press-centre/reports/A-North-Sea-electricity-grid-(r)evolution . $\operatorname{pdf}$

GWEC (Ed.), 2011. Global Wind Energy Council: Global Wind Report; Annual Market Update 2010. GWEC.

Haase, T., 2006. Anforderungen an eine durch Erneuerbare Energien geprägte Energieversorgung - Untersuchung des Regelverhaltens von Kraftwerken und Verbundnetzen (Requirement for power supply with major shares of renewables - analysis of the power plant and network control). Ph.D. thesis, Fakultät für Informatik und Eletroktechnik der Universität Rostock.

Heide, D., von Bremen, L., Greiner, M., Hoffmann, C., Speckmann, M., Bofinger, S., 2010. Seasonal optimal mix of wind and solar power in a future, highly renewable europe. Renewable Energy 35 (11), 2483 - 2489.

Heitmann, N., 2005. Solution of energy problems with the help of linear programming. Ph.D. thesis, Naturwissenschaftliche Fakultät der Universität Augsburg. 
Heitmann, N., Hamacher, T., 2009. Stochastic Model of the German Electricity System. Energy Systems: Optimization in the Energy Industry 3, $365-385$.

IEA, 2010a. International Energy Agency: Electricity Information 2010. OECD.

IEA, 2010b. International energy agency: Interactive renewable energy calculator: Recabs.

URL http://www. recabs .org/

IEA (Ed.), 2010c. International Energy Agency: World Energy Outlook 2010. Organisation for Economic Co-operation and Development OECD, Paris.

IEA (Ed.), 2011. International Energy Agency: World Energy Outlook 2011. Organisation for Economic Co-operation and Development OECD, Paris.

Jacobsen, H. K., Zvingilaite, E., 2010. Reducing the market impact of large shares of intermittent energy in Denmark. Energy Policy 38 (7), 3403 3413, large-scale wind power in electricity markets with Regular Papers.

URL http://www.sciencedirect.com/science/article/pii/ S0301421510000959

Kerner, W., 2007. Ten-energy policy; trans-european energy networks: Dg $\operatorname{tren} / \mathrm{c} 2$.

URL http://www.trade-wind.eu/fileadmin/documents/Seminar_ UCTE/presentations/7_Kerner_EC.pdf

Leuthold, F., Jeske, T., Weigt, H., von Hirschhausen, C., 2009. When the Wind Blows Over Europe. A Simulation Analysis and the Impact of Grid 
Extensions. Electricity Markets Working Papers WP-EM-31.

URL http://www.tu-dresden.de/wwbwleeg/publications/wp_em_31_ Leuthold_etal_EU_wind.pdf

MacCormack, J., Hollis, A., Zareipour, H., Rosehart, W., 2010. The largescale integration of wind generation: Impacts on price, reliability and dispatchable conventional suppliers. Energy Policy 38 (7), 3837 - 3846, large-scale wind power in electricity markets with Regular Papers.

McKinsey, KEMA, The Energy Futures Lab at Imperial College London, Oxford Economics, European Climate Foundation, 2010. RoadMap 2050: A practical guide to a prosperous, low-carbon Europe: Technical Analysis: Volume I.

URL http://www.roadmap2050.eu/

Neuhoff, K., 2005. Large-scale deployment of renewables for electricity generation.

URL http://oxrep.oxfordjournals.org/cgi/content/abstract/21/ $1 / 88$

NordPool, 2010. Nordic power exchange. URL www. nasdaqomxcommodities.com

Ockenfels, A., Grimm, V., Zoettl, G., 2008. Strommarktdesign: Preisbildung im Auktionsverfahren für Stromkundenkontrakte an der EEX; Gutachten im Auftrag der European Energy Exchange AG zur Vorlage an die Sächsiche Börsenaufsicht. 
URL http://www.eex.com/de/document/38614/gutachten_eex_ ockenfels.pdf

OffshoreGrid, 2010. Offshore wind project: Inventory list of possible wind farm locations with installed capacities for the 2020 and 2030 scenarios. URL http://www . offshoregrid.eu/index.php/results

Öko-Institut, 2008. Globales Emissions-Modell Integrierter Systeme (GEMIS) Version 4.5.

URL www.gemis.de

OMEL, 2010. Mercado de electricidad.

URL www.omel.es

Platts, 2009. Data Base Description and Research Methodology: UDI Wold Electric Power Plant Data Base (WEPP).

URL

http://www.platts.com/Products/ worldelectricpowerplantsdatabase

PWC, PriceWaterHouseCoopers, Potsdam Institute for Climate Impact Research, International Institute for Applied System Analysis, European Climate Forum, 2010. 100\% Renewable Energy: A Roadmap to 2050 for Europe and North Africa.

Sensfuss, F., Ragwitz, M., Genoese, M., 2008. The merit-order effect: A detailed analysis of the price effect of renewable electricity generation on spot market prices in germany. Energy Policy 36 (8), 3086 - 3094.

TradeWind, 2009. Integrating Wind - TradeWind: Developing Europe's power market for the large-scale integration of wind power, Study by Sintef 
Energieforskning AS, Riso DTU, 3E, Kema Nederland BV, Technical Research Centre of Finland, Garrad Hassan and Partner Ltd, Tracabel Engineering and Deutsche Energie-Agentur GmbH (dena).

URL http://www.ewea.org/fileadmin/ewea_documents/documents/ publications/reports/TradeWind_Report_01.pdf

Twomey, P., Neuhoff, K., 2010. Wind power and market power in competitive markets. Energy Policy 38 (7), 3198-3210.

Weigt, H., Jeske, T., Leuthold, F., von Hirschhausen, C., 2010. Take the long way down: Integration of large-scale North Sea wind using HVDC transmission. Energy Policy 38 (7), $3164-3173$.

Wheeler, D., Ummel, K., 2008. Calculating CARMA: Global Estimation of CO2 Emissions from the Power Sector. Center for Global Development Working Paper Number 145, 1-36.

Woo, C., Horowitz, I., Moore, J., Pacheco, A., 2011. The impact of wind generation on the electricity spot-market price level and variance: The Texas experience. Energy Policy 39 (7), 3939 - 3944, special Section: Renewable energy policy and development. URL http://www.sciencedirect.com/science/article/pii/ S0301421511002813 